\title{
Treatment of Elderly Bedridden Patients with Removable Dentures to Promote Their Daily Physical Activities: A Case-Control Study
}

\author{
Yoshiro Fujii \\ Shin-Kobe Dental Clinic, Kobe, Japan \\ Email: shin-kobe-dentalclinic@s9.dion.ne.jp
}

How to cite this paper: Fujii, Y. (2020) Treatment of Elderly Bedridden Patients with Removable Dentures to Promote Their Daily Physical Activities: A Case-Control Study. Advances in Aging Research, 9, 116125 .

https://doi.org/10.4236/aar.2020.96009

Received: September 23, 2020

Accepted: November 20, 2020

Published: November 23, 2020

Copyright $\odot 2020$ by author(s) and Scientific Research Publishing Inc. This work is licensed under the Creative Commons Attribution International License (CC BY 4.0).

http://creativecommons.org/licenses/by/4.0/

\begin{abstract}
Bedridden patients remain in bed for various reasons, such as chronic illness, old age, and disability, and they cannot perform self-care activities completely or partially. The provision of care for bedridden patients is a major issue in the aging population. Effective rehabilitation is associated with several factors such as cooperation between the patient and the medical staff, selection of effective facilities, and the financial burden. The objective of this study was to evaluate the effect on the activities of daily living (ADL) of occlusion restoration using removable dentures in bedridden older people. This case-control study comprised 32 bedridden older patients who were divided into two groups as follows: denture $(n=18)$ and no-denture $(n=14)$. No rehabilitation was provided to any of the patients. The patients were evaluated 3 months after placing the denture, and the ADLs were compared between the two groups. Of the 18 bedridden patients who received removable dentures, $55.6 \%$ demonstrated improvements in the ADLs, and the effects persisted for at least 3 months. No improvement in the ADL was observed in the no-denture group. The results of this study suggested that adequate occlusal support can improve the ADL of the elderly. Thus, it is important to take care of oral health early in life in order to maintain oral health, which could help prevent the decrease in the ADL during the later stages of life.
\end{abstract}

\section{Keywords}

Bedridden Patient, Activities of Daily Living (ADL), Older Patient, Occlusal Treatment, Denture 


\section{Introduction}

Being bedridden implies the confinement of an individual to the bed [1]. Bedridden patients stay in bed for various reasons, including chronic illness, old age, and disability, which results in the inability to perform self-care activities. They need the help of others and are usually cared for by family members, paid caregivers, and/or health professionals [2]. For people with disabilities, the inability to transfer them to a chair and the ability of caregivers are associated with continuous confinement to the bed [3]. Being bedridden leads many complications such as loss of muscle strength and endurance. Contractures, osteoporosis from disuse and the degeneration of joints can occur. Being confined to bed can add to the likelihood of developing an increased heart rate, decreased cardiac output, hypotension, and thromboembolism [4]. One of the main issues with regard to the care of the disabled and bedridden is the financial burden entailed and bedridden patients are dependent on the family for their immediate needs, particularly those related to hygiene. The issue of who will care and provide for the disabled and aged is a matter of debate throughout the world [5]. A patient is bedridden due to a decline in physical function; hence, attempts have been made to recover the functions by rehabilitation. Canedo et al. reported that an intensive rehabilitation program was significantly beneficial for hospitalized patients [6]. However, the provision of effective rehabilitation is associated with issues such as the relationship between the patient and the medical staff, the selection of effective facilities, and the financial burden. In order to avoid these issues, the improvement of ADL is essential. Activities of daily living (ADLs) are the things we normally do in daily living including any daily activity we perform for self-care (such as feeding ourselves, bathing, dressing, grooming), work, homemaking, and leisure [7]. Some studies examined the effect on the condition of the bedridden patient of altering the environment in the oral cavity, which is thought to affect the brain function [8] [9]. Many clinical studies indicate a close relationship between dental and systemic conditions, and have reported that dental treatment can be used to treat systemic diseases; in particular, the effects of occlusion [10] [11] [12] [13] [14], jaw posture [15] [16] [17], temporomandibular joint conditions [18]-[23], focal infection [24] [25], and electromagnetic waves emitted by dental materials [26] on systemic conditions have been investigated. Recently, an association between low back pain and a harmful stimulation of the oral mucosa by natural teeth was reported [27]. Moreover, Miyaji S. reported the relationship between forearm tendinitis and irritation of oral mucosa by teeth [28].

However, to date there are no reports on the effect of dental treatment on the activities of daily living (ADL) in the bedridden elderly population.

This study was designed to evaluate the effect of dental treatment on ADL in bedridden older people. 


\section{Methods}

\subsection{Study Design}

This case-control study compared the ADLs between bedridden elderly people who used dentures and those without dentures. The study was conducted from 1995 to 2005, and the elderly patients were treated at the hospital (Yoshioka hospital in Kasugai city in Aichi-pre., Japan), home, or dental clinic.

\subsection{Patients}

A total of 36 bedridden elderly patients were enrolled in the study. However, three of them did not provide consent for the investigation and one was not available for follow-up; hence, 32 patients were finally included in the study.

There were 6 men and 26 women bedridden patients (age range, 70 - 89 years; mean age, 82 years). None of them had used a denture prior to the study. The inclusion criteria were as follows: $>70$ years old, did not use a denture and did not receive any rehabilitation and belonged to rank $\mathrm{B}$ or $\mathrm{C}$ in Table 1 . Table 1 shows the criteria for evaluating the degree of ADL impairment in the disabled elderly (Ministry of Health and Welfare, 1991, Japan). The patients in the current study were ranked between $\mathrm{B} 1$ and $\mathrm{C} 2$ on the ADL scale (B1, 14; B2, 11; C1, 5; and C2, 2). All patients had lost more (not including wisdom teeth) than 18 teeth or less along with loss of occlusal support between the upper and lower teeth.

The patients were divided into two groups as follows: denture group ( $\mathrm{n}=$ $18)$ and no-denture group $(n=14)$. Dentures were fabricated for the patients in the denture group based on the Bi-Digital O-Ring test [29] [30] wherein the ideal occlusal position of the denture was determined by assessing the strongest

Table 1. Criteria for activity of daily living for elderly people with impairments.

\begin{tabular}{|c|c|c|}
\hline Situation & Rank & Criteria \\
\hline $\begin{array}{l}\text { Independent } \\
\text { Living }\end{array}$ & $\mathrm{J}$ & $\begin{array}{l}\text { These individuals are impaired in some way but mostly lead } \\
\text { independent lives and can go out on their own. } \\
\text { 1) They use public transportation. } \\
\text { 2) They go out in the neighborhood. }\end{array}$ \\
\hline Pre-bedridden & A & $\begin{array}{l}\text { These individuals can move independently when indoors but } \\
\text { require assistance when going out. } \\
\text { 1) They go out with assistance, spending most of the day out of bed. } \\
\text { 2) They go out infrequently and spend more time in bed. }\end{array}$ \\
\hline Bedridden & B & $\begin{array}{l}\text { These individuals require some assistance at home and spend } \\
\text { their days in bed, sitting upright. } \\
\text { 1) They use a wheelchair and eat meals out of bed. } \\
\text { 2) They need assistance when using their wheel chair. }\end{array}$ \\
\hline Bedridden & $\mathrm{C}$ & $\begin{array}{l}\text { These individuals are bedridden and require assistance to eat, } \\
\text { change clothes, and use the rest room. } \\
\text { 1) They change positions without assistance. } \\
\text { 2) They require assistance to change positions. }\end{array}$ \\
\hline
\end{tabular}

Ministry of Health and Welfare, 1991, Japan. 
grip strength over a range of biting positions [12]. The patients in the no-denture group did not utilize any denture, including those that were made by the author. The effect of denture use on the ADLs was evaluated for 3 months after denture placement and compared with that in the no-denture group. No rehabilitation was provided to any of the patients. Of the 32 patients, 14 had cerebrovascular diseases (43.8\%), 10 had dementia (31.3\%), 4 had cerebrovascular disease and dementia (12.5\%), and 4 had other injuries or issues (12.5\%).

The efficacy of the treatment was assessed by evaluating the criteria of ADL impairment in the older patients (Table 1). Those who moved up by three or more steps on the ADL scale (for example, $\mathrm{C} 2 \rightarrow \mathrm{B} 1, \mathrm{C} 2 \rightarrow \mathrm{A} 2, \mathrm{~B} 1 \rightarrow \mathrm{J} 2$, or B1 $\rightarrow$ J1) after the dental treatment were considered to demonstrate significant improvement. Those who moved up by two steps demonstrated moderate improvement and those who moved up one step or less on the ADL scale were considered to present with no improvement. The patients were evaluated for 3 months after the placement of the denture (Figure 1).

\subsection{Statistical Analysis}

All statistical analyses were performed using the $\chi^{2}$ test to compare the mean values between the two groups (Windows Excel, 2016). A p-value is $0.000761<$ 0.01 was considered significant (Table 2).

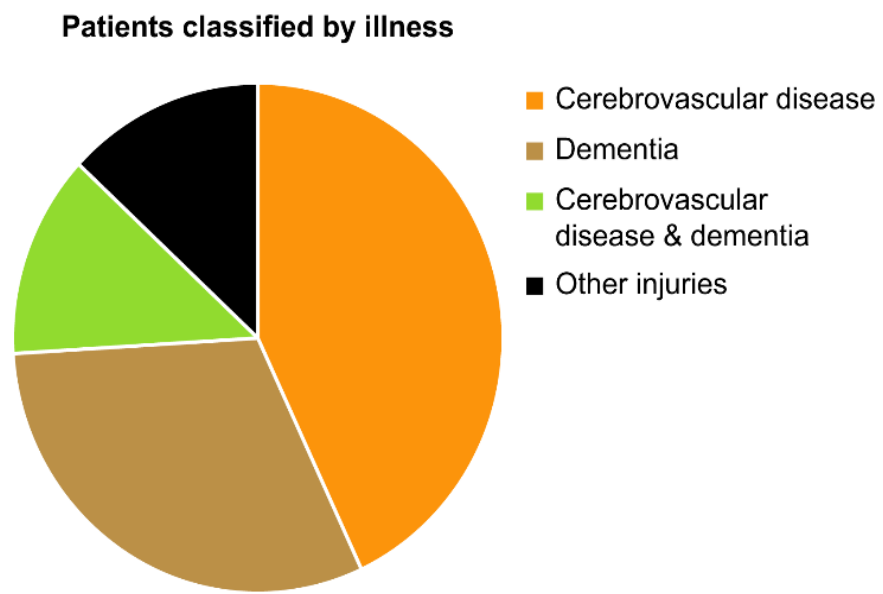

Figure 1. Classification of the patients based on their illnesses i.e. cerebrovascular diseases $(43.8 \%)$, dementia $(31.3 \%)$, cerebrovascular disease and dementia (12.5\%), and other injuries or issues (12.5\%).

Table 2. Data used for the $\chi^{2}$ test.

\begin{tabular}{cccc}
\hline & $\begin{array}{c}\text { Significant or } \\
\text { moderate improvement }\end{array}$ & No improvement & Total \\
\hline Denture group & 10 & 8 & 18 \\
No denture group & 0 & 14 & 14 \\
Total & 10 & 22 & 32 \\
\hline
\end{tabular}




\section{Results}

Among the 18 patients in the denture group, 7 (38.9\%) showed significant improvement, 3 (16.7\%) showed moderate improvement, and 8 (44.4\%) showed no improvement (Figure 2). The effects persisted for at least 3 months. A 70-year-old patient in Figure 3(a) was bedridden due to cerebral infarction and could not move without assistance. He did not respond to his name and was unable to eat, due to which he was fed intravenously. Two weeks after the denture placement, the patient could sit upright (Figure 3(b)), and one month later he could eat and move around the hospital in a wheelchair without rehabilitation. Moreover, he could walk short distances with a cane. After learning how to eat again, his status was changed from $\mathrm{C} 2$ to B1, demonstrating significant improvement, and he was, subsequently, discharged from the hospital (Figure $3(\mathrm{c}))$.

In Figure 4(a), an 89-year-old woman with ADL rank C2 was able to walk with a cane until one year prior to this study. She was hospitalized for a routine checkup, and her doctor in charge found no abnormalities. While in the hospital,

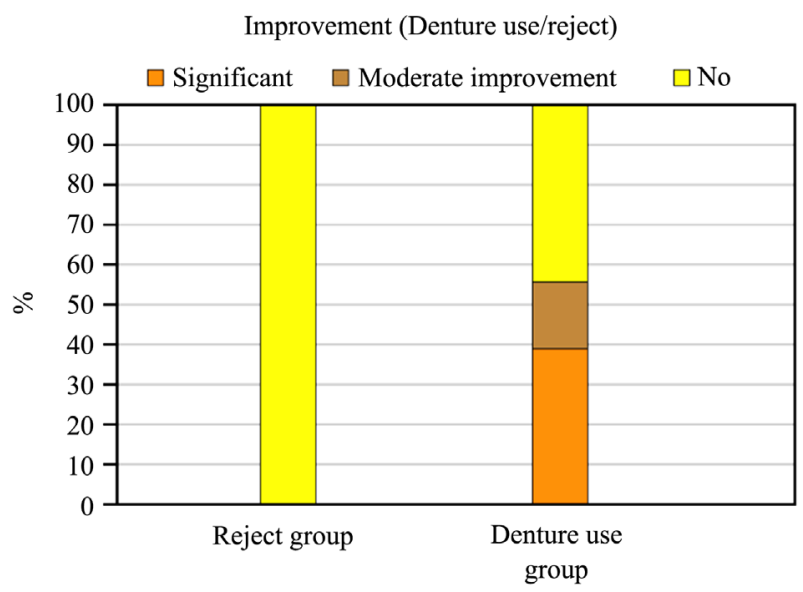

Figure 2. Graph showing the proportion of patients who demonstrated improvements in the ADLs in the denture group. No improvement was observed in the no-denture group.

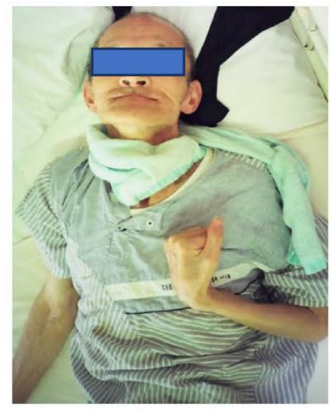

(a)

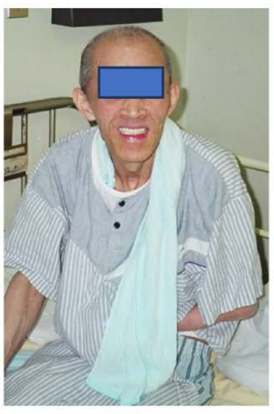

(b)

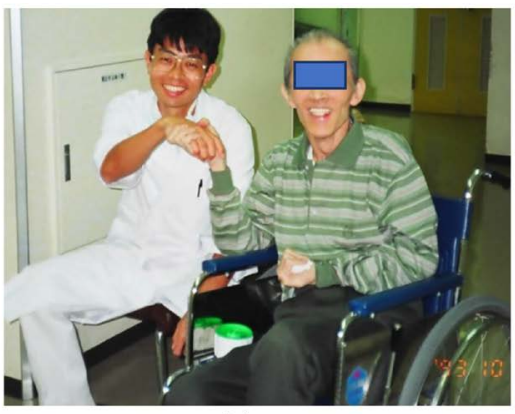

(c)

Figure 3. A 70-year-old bedridden patient after cerebral infarction. (a) He could not move without assistance and did not respond to his name. He was unable to eat and was fed intravenously; (b) He could sit upright 2 weeks after denture placement; (c) He was discharged from the hospital a month later. 


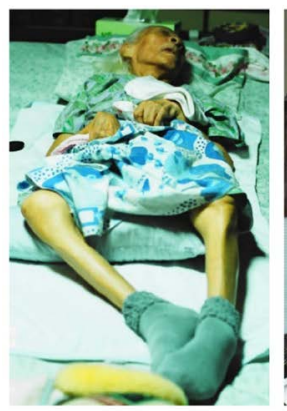

(a)

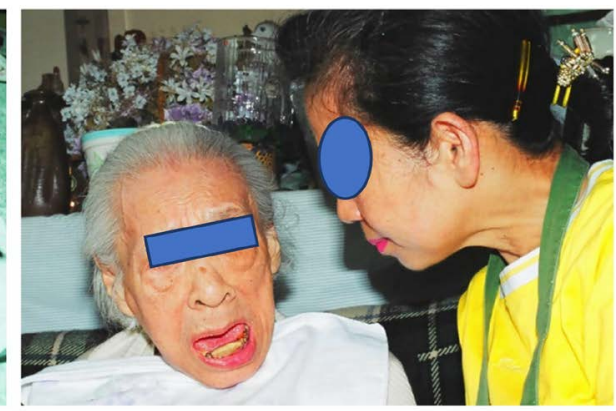

(b)

Figure 4. An 89-year-old bedridden woman. (a) She could not open her eyes, respond to questions, remain conscious, or change her position. She did not use her dentures although she had partial dentures; (b) Two weeks after her dentures were fixed and placed, she could open her eyes. Her ADL gradually improved; she could respond to questions and eat with assistance.

she was instructed not to wear her dentures. Her ADL dropped suddenly and she became bedridden. She was released from the hospital and cared for at home where her condition continued to decline; she could not open her eyes, respond to questions, remain conscious, or change her position. Two weeks after her dentures were fixed and placed, she could open her eyes. Her ADL gradually improved, she could respond to questions and eat with assistance (Figure 4(b)). Her ADL rank improved from $\mathrm{C} 2$ to $\mathrm{B} 2$, demonstrating moderate improvement. In order to watch the actual experiment described in this case, please visit the YouTube movie: The patient who had her denture removed, saw her quality of life decline [31]. https://www.youtube.com/watch?v=ox4NNtqM_UU

Additional videos of patients who presented with improvements in the ADLs in this study may be viewed using the following links:

A bedridden person was able to walk because of wearing dentures https://www.youtube.com/watch?v=1vJiXlaR3M0 [32].

Dental treatment for a bedridden old person with Parkinson's disease and lower back pain https://www.youtube.com/watch?v=Zc-YLeVvSoI\&t=1s [33].

On the other hand, the patients in the no-denture group showed no improvement.

No significant difference in improvement was observed based on the type of disease among the patients.

\section{Discussion}

This study aimed to evaluate the effect of dental treatment on the ADL in bedridden older people. In results suggesting that restoration of the occlusal support might prove effective against ADL impairment, approximately $56 \%$ of the people in the denture group demonstrated improvements in the ADL, whereas no improvement was observed in the no-denture group. All the dentures were fabricated by referring to the Bi-Digital O-Ring test [29] [30]; the occlusal position of the denture was determined by assessing the strongest grip strength over 
a range of biting positions [12]. When grip strength was difficult to detect because of weak muscles and other reasons, an indirect method was used in which a third person was interposed between the patient and the examiner [29].

Approximately $28.6 \%$ and $70.0 \%$ of patients with cerebrovascular disease and dementia, respectively, rejected the use of the dentures. The cause for rejection might be due to anxiety related to the placement and adjustment of the denture and the daily care involved. To increase the use of a denture within the population of patients with dementia, both the patients and caretakers must be aware of the efficacy of dental treatment, with patients with dementia may be finding it difficult to understand the purpose of the denture.

Nonetheless, the underlying reason for the success of this treatment in the denture group remains unclear. Beneficial signals may stimulate the brain via the trigeminal nerve, which is the largest of the 12 cranial nerves [8] [24]. Hosoi et al. [9] analyzed the effect of complete dentures and partial dentures on brain function activity using an electroencephalogram (EEG) and reported that brain function activity was indeed enhanced with wearing dentures; therefore, brain functional activation was achieved in denture wearing elderly patients at risk of brain activity deterioration.

The limitation of the present study is that it was performed by one person, and the number of patients enrolled was insufficient. Therefore, additional studies using a larger sample size are required to confirm our findings. Particularly, in advanced countries, society is aging, and the decrease in the ADL of the elderly is becoming a major social issue. Occlusal treatment seems to be useful for solving this issue, with almost no side effects or pain. Such surveys conducted at the national level, including sufficient samples, would be necessary to obtain more accurate data. Furthermore, cooperation between the dental and medical faculties is of utmost importance during the treatment of these patients. It is important to clarify the relationship between dental and systemic conditions in the future.

\section{Conclusion}

The results of this study suggested that occlusal support improves the ADL, and they indicated that denture use affects not only the oral cavity but also the body in general. To promote the ADL in older people and provide improved care for seniors, cooperation between the dental and medical faculties is necessary. The findings of this study indicate that the maintenance of oral health may aid in preventing ADL impairment; therefore, it is important to take care of oral health from a younger age.

\section{Acknowledgements}

We would like to give a special thanks to Enago (https://www.enago.jp) for the English language review. We thank the participants of this research for their valuable contributions. 


\section{Conflicts of Interest}

The author declares no conflicts of interest regarding the publication of this paper.

\section{References}

[1] Definition of Bedridden (2020). https://www.merriam-webster.com/dictionary/bedridden

[2] Vieira, H.F., Bezerra, A.L.D., Sobreira, M.V.S., Silva, J.B.D., Feitosa, A.D.N.A. and Paraíba, F.S.M.C. (2015) 60-Nursing Care Patient Bedridden in Household. A Systematic Review. FIEP Bulletin, 85, 253-257. https://doi.org/10.16887/85.a2.60

[3] Forbes, D.A. (2009) Being Bedridden Was a Slow Process Influenced by Interactions with the Environment, Nurses, and Social Ties. Evidence-Based Nursing, 12, 64. https://doi.org/10.1136/ebn.12.2.64

[4] Kane, E. (2020) How to Care for a Bedridden Elderly Person at Home. https://seniorsafetyadvice.com/how-to-care-for-a-bedridden-elderly-person-at-hom e/

[5] Bains, P. and Minhas, A.S. (2011) Profile of Home-Based Caregivers of Bedridden Patients in North India. Indian Journal of Community Medicine, 36, 114-119. https://doi.org/10.4103/0970-0218.84129

[6] Canedo, E., Nunes Velloso, V., Calejman, L. and Leidi, N. (2012) Motor and Respiratory Intensive Rehabilitation in Bedridden Patients. Critical Care, 16, Article No. 527. https://doi.org/10.1186/cc11134

[7] Activities of Daily Living (2020). https://adlexpert.weebly.com

[8] Fujii, Y. (2016) Two Cases of Severe Dementia Showing Dramatic Improvement after Denture Placement. Advances in Alzheimer's Disease, 5, 46-52. https://doi.org/10.4236/aad.2016.52004

[9] Hosoi, T., Morokuma, M., Shibuya, N. and Yoneyama, Y. (2011) Influence of Denture Treatment on Brain Function Activity. Japanese Dental Science Review, 47, 56-66. https://doi.org/10.1016/j.jdsr.2010.09.001

[10] Fujii, Y. (2015) Orthodontic Treatment to Improve Hip Joint Mobility and Balance. Journal of Dentist, 3, 29-32. https://doi.org/10.12974/2311-8695.2015.03.01.5

[11] Karppinen, K., Eklund, S., Suoninen, E., Eskelin, M. and Kirveskari, P. (1999) Adjustment of Dental Occlusion in Treatment of Chronic Cervicobrachial Pain and Headache. Journal of Oral Rehabilitation, 26, 715-721.

[12] Fujii, Y. (2019) Evaluation of a Mouthguard Customized Using the Occlusal Position during Maximal Grip Strength to Improve Sports Performance. A Case Report. Case Reports in Clinical Medicine, 8, 147-151. https://doi.org/10.4236/crcm.2019.86017

[13] Bracco, P., Deregibus, A. and Piscetta, R. (2004) Effects of Different Jaw Relations on Postural Stability in Human Subjects. Neuroscience Letters, 356, 228-230. https://doi.org/10.1016/j.neulet.2003.11.055

[14] Gangloff, P., Louis, J.P. and Perrin, P.P. (2000) Dental Occlusion Modifies Gaze and Posture Stabilization in Human Subjects. Neuroscience Letters, 293, 203-206. https://doi.org/10.1016/S0304-3940(00)01528-7

[15] Gelb, H., Mehta, N.R. and Forgione, A.G. (1996) The Relationship between Jaw Posture and Muscular Strength in Sports Dentistry: A Reappraisal. The Journal of Craniomandibular \& Sleep Practice, 14, 320-325. 
https://doi.org/10.1080/08869634.1996.11745984

[16] Smith, S.D. (1978) Muscular Strength Correlated to Jaw Posture and the Temporomandibular Joint. The New York State Dental Journal, 44, 278-285.

[17] Al-Abbasi, H., Mehta, N.R., Forgione, A.G. and Clark, R.E. (1999) The Effect of Vertical Dimension and Mandibular Position on Isometric Strength of the Cervical Flexors. The Journal of Craniomandibular \& Sleep Practice, 17, 85-92. https://doi.org/10.1080/08869634.1999.11746082

[18] Watanabe, E.K., Yatani, H., Kuboki, T., Matsuka, Y., Terada, S., Orsini, M.G. and Yamashita A. (1998) The Relationship between Signs and Symptoms of Temporomandibular Disorders and Bilateral Occlusal Contact Patterns during Lateral Excursions. Journal of Oral Rehabilitation, 25, 409-415. https://doi.org/10.1046/j.1365-2842.1998.00262.x

[19] Kobayashi, M., Yabushita, T., Zeredo, J.L., Toda, K. and Soma, K. (2007) Splenius Muscle Activities Induced by Temporomandibular Joint Stimulation in Rats. Brain Research Bulletin, 72, 44-48. https://doi.org/10.1016/j.brainresbull.2006.10.031

[20] Matsumoto, M.A., Matsumoto, W. and Bolognese, A.M. (2002) Study of the Signs and Symptoms of Temporomandibular Dysfunction in Individuals with Normal Occlusion and Malocclusion. The Journal of Craniomandibular \& Sleep Practice, 20, 274-281. https://doi.org/10.1080/08869634.2002.11746219

[21] Ciancaglini, R., Gherlone, E.F., Redaelli, S. and Radaelli, G. (2002) The Distribution of Occlusal Contacts in the Intercuspal Position and Temporomandibular Disorder. Journal of Oral Rehabilitation, 29, 1082-1090.

[22] Lim, P.F., Smith, S., Bhalang, K., Slade, G.D. and Maixner, W. (2010) Development of Temporomandibular Disorders Is Associated with Greater Bodily Pain Experience. The Clinical Journal of Pain, 26, 116-120. https://doi.org/10.1097/AJP.0b013e3181c507ef

[23] Sakaguchi, K., Mehta, N.R., Abdallah, E.F., Forgione, A.G., Hirayama, H., Kawasaki, T. and Yokoyama, A. (2007) Examination of the Relationship between Mandibular Position and Body Posture. The Journal of Craniomandibular \& Sleep Practice, 25, 237-249. https://doi.org/10.1179/crn.2007.037

[24] Fujii, Y. (2020) Two Cases of Parkinson's disease for which Dental Treatment Was Effective. Advances in Parkinson's Disease, 9, 13-19. https://doi.org/10.4236/apd.2020.92002

[25] Tanalka, T., Sato, T. and Yozeki, H. (2009) Dental Infection Associated with Nummular Eczema as an Overlooked Focal Infection. Journal of Dermatology, 36, 462-465.

[26] Fujii, Y. (2019) Dental Treatment with a Gold Alloy Cast Crown for Severe Lumbago. Open Journal of Stomatology, 9, 21-27. https://doi.org/10.4236/ojst.2019.92003

[27] Fujii, Y. (2015) Dental Stimulation to the Buccal Mucous Membrane Cases Lumbago: A Report of Two Cases. Case Reports in Clinical Medicine, 4, 289-296. https://doi.org/10.4236/crcm.2015.48058

[28] Miyaji, S. (2020) Lower Back Pain and Forearm Tendinitis Linked to Irritation of Oral Mucosa by Teeth. Case Reports in Clinical Medicine, 9, 295-302. https://doi.org/10.4236/crcm.2020.99042

[29] Omura, Y. (1993) Bi-Digital O-Ring Test for Imaging and Diagnosis of Internal Organs of a Patient. US Patent No. 5188107.

[30] Bi-Digital O-Ring Test (BDORT). http://bdort.org/

[31] YouTube Movie: The patient who had her denture removed, saw her Quality of life 
decline. https://www.youtube.com/watch?v=ox4NNtqM_UU

[32] YouTube Movie: A Bedridden Person Was Able to Walk because of Wearing Dentures. https://www.youtube.com/watch?v=1vJiXlaR3M0

[33] YouTube Movie: Dental Treatment for a Bedridden Old Person with Parkinson's Disease and Lower Back Pain.

https://www.youtube.com/watch?v=Zc-YLeVvSoI\&t=1s 